ARTICLE

Table 1 Case records and patients reporting the listed term

\begin{tabular}{lcl}
\hline Inappropriate term & $\begin{array}{l}\text { Case note review } \\
(n=1259)\end{array}$ & $\begin{array}{l}\text { Patient survey } \\
(n=648)\end{array}$ \\
\hline Abortion & $125(9.9 \%, 8.4-11.7)$ & $27(4.2 \%, 2.9-6.0)$ \\
Blighted ovum & $65(5.2 \%, 4.1-6.5)$ & $38(5.9 \%, 4.3-7.9)$ \\
Incompetent cervix & $2(0.2 \%, 0-0.6)$ & $6(0.9 \%, 0.4-2.0)$ \\
Pregnancy failure & $72(5.7 \%, 4.6-7.1)$ & $95(14.7 \%, 12.1-17.6)$ \\
\hline
\end{tabular}

The results are given as number (percentage; $95 \% \mathrm{CI}$ )

\section{Results}

Overall, 942 case notes for miscarriages and 337 for ectopic pregnancies were sought; 934 records for miscarriages and 325 for ectopic pregnancies were obtainable for review representing a combined retrieval rate of $98 \%$. A total of 649 questionnaires were returned from a mailing of 1750 , representing a $37 \%$ response rate. One questionnaire was excluded from analysis because the woman had presented with hyperemesis and did not fulfil the inclusion criteria. The remaining 648 replies comprised 323 women with pregnancy loss, 307 women with threatened miscarriage (i.e. viable pregnancy at discharge), 15 women who were unsure of their diagnosis at discharge and three women who left the diagnosis question blank.

The results are summarised in Table 1. Generally, women reported low levels of inappropriate terminology usage by health professionals. An exception was the term 'pregnancy failure', heard by approximately 1 in 7 women. Relatively high levels of usage of 'abortion' were found in case records, with 1 in 10 hospital records containing this term.

\section{Discussion}

We acknowledge there are limitations to our study. Due to considerations for confidentiality and consent to participate, we were unable to mail questionnaires to women whose case records we reviewed retrospectively, having instead to perform a prospective questionnaire, and consequently cannot make a direct correlation between the two audit tools. In addition, the low response rate to the patient survey introduces potential selection bias, limiting how generalisable these results are to other clinical settings. However, the principal findings from this study are derived from the case note review where there was a very high retrieval rate.

The use in scientific journals of inappropriate terminology for miscarriage has previously been highlighted. ${ }^{6,7}$ These papers suggest that, over the past two decades, there has been a change in terminology used in the European literature. However, we can find no previous study measuring use of inappropriate terminology during routine clinical practice. Use of appropriate terminology may, or may not, reduce women's distress at pregnancy loss $;{ }^{8}$ however, we believe that a commonsense approach of avoiding ambiguous terms such as 'abortion' could not increase this distress. The term 'miscarriage' is generally understood and accepted by members of the public. Patients now have access to their case records. In order to meet national recommendations on terminology for early pregnancy loss, clinicians should not only say 'miscarriage' but also write it.

Statements on funding and competing interests

Funding. SPCERH is funded through NHS Quality Improvement Scotland.

Competing interests. None identified.

References

1 Frost M, Condon JT. The psychological sequelae of miscarriage: a critical review of the literature. Aust N Z J Psychiatry 1996; 30: $54-62$.

2 Prendiville WJ. Miscarriage: epidemiological aspects. In: Grudzinskas JG, O'Brien PMS (eds), Problems in Early Pregnancy: Advances in Diagnosis and Management. London, UK: RCOG Press, 1997; Chapter 1, 3-18.

3 Royal College of Obstetricians and Gynaecologists (RCOG). The Management of Early Pregnancy Loss. London, UK: RCOG Press, 2000 .

4 Scottish Office Department of Health National Medical Advisory Committee. The Management of Early Pregnancy Loss: A Statement of Good Practice. Edinburgh, UK: The Stationery Office, 1996.

5 Scottish Programme for Clinical Effectiveness in Reproductive Health (SPCERH). Scottish Audit of the Management of Early Pregnancy Loss. Edinburgh, UK: SPCERH, 2003.

6 Chalmers B. Terminology used in early pregnancy loss. Br J Obstet Gynaecol 1992; 99: 357-358.

7 Hutchon DJ. Understanding miscarriage or insensitive abortion: time for more defined terminology? Am J Obstet Gynecol 1998; 179: 397-398

8 Freeling P, Gask L. Sticks and stones: changing terminology is no substitute for good consultation skills. BMJ 1998; 317: 1028-1029.

\title{
International Travelling Scholarship of the Faculty
}

The Faculty of Family Planning and Reproductive Health Care has decided to offer a scholarship for those Faculty members who are interested in going abroad to visit international colleagues, services, research or educational establishments in order to learn about some aspect of family planning or reproductive health care. The Faculty will award the International Travelling Scholarship for a maximum of $£ 2000$ for five consecutive years. The recipient of the award will be required to give a presentation at a Faculty conference.

The Faculty Officers will consider applications for the award and make a recommendation to Faculty Council. Applications for the scholarship are restricted to members of the Faculty.

Applications should include the following details: country and establishment(s) to be visited, aims of visit, details of visit and benefits, together with a brief curriculum vitae and full contact details.

Enquires about the Scholarship and submissions should be e-mailed to: fulden@ffprhc.org.uk.

Completed applications must be received at the Faculty office by 1 April annually.

Entries should be submitted to: International Travelling Scholarship, Faculty of Family Planning and Reproductive Health Care of the RCOG, 27 Sussex Place, Regent's Park, London NW1 4RG, UK. 